OPEN ACCESS

Edited by: Maria Felicia Faienza, Università degli studi di Bari Aldo Moro, Italy

Reviewed by: Jameela Banu, University of Texas Rio

Grande Valley, USA Jawed Akhtar Siddiqui, University of Nebraska

Medical Center, USA

${ }^{*}$ Correspondence: Mingxiang Yu yu.mingxiang@zs-hospital.sh.cn; Xinhua Qu xinhua_qu@126.com

Specialty section: This article was submitted to Bone Research, a section of the journa Frontiers in Endocrinology

Received: 18 January 2017 Accepted: 18 April 2017 Published: 03 May 2017

Citation:

Zhao C, Liang J, Yang Y, Yu M and QuX (2017) The Impact of

Glucagon-Like Peptide-1 on Bone Metabolism and Its

Possible Mechanisms.

Front. Endocrinol. 8:98 doi: 10.3389/fendo.2017.00098

\section{The Impact of Glucagon-Like Peptide-1 on Bone Metabolism and Its Possible Mechanisms}

\author{
Chenhe Zhao ${ }^{1}$, Jing Liang ${ }^{1}$, Yinqiu Yang ${ }^{1}$, Mingxiang $\mathrm{Yu}^{1 *}$ and Xinhua $Q u^{2 *}$ \\ ${ }^{1}$ Department of Endocrinology, Zhongshan Hospital, Fudan University, Shanghai, China, ${ }^{2}$ Department of Orthopedics, \\ Shanghai Key Laboratory of Orthopaedic Implants, Shanghai Ninth People's Hospital, Shanghai Jiaotong University \\ School of Medicine, Shanghai, China
}

The impact of antidiabetic drugs on bone metabolism is drawing increasing attention due to the discovery of a correlation between type 2 diabetes mellitus (T2DM) and osteoporosis. Glucagon-like peptide-1 (GLP-1) receptor agonists are a novel and promising class of drugs for T2DM, which may also have clinical applications in bone tissue disorders. This review examines the impact of GLP-1 on bone metabolism, including enhancement of bone mineral density and improvement of bone quality. However, the precise effect of GLP-1 on fracture risk has not been unambiguously defined. This review also summarizes our current understanding of the mechanisms by which GLP-1 affects bone metabolism. GLP-1 may act on bone by promoting bone formation, inhibiting bone resorption, and affecting the coordination of the two processes. We describe molecular pathways and proteins, such as Wnt and calcitonin, that are associated with GLP-1 and bone tissue. The specific processes and related molecular mechanisms of the effects of GLP-1 on bone metabolism need to be further explored and clarified.

Keywords: glucagon-like peptide-1, osteogenesis, bone resorption, osteoporosis, diabetes mellitus

\section{INTRODUCTION}

Diabetes mellitus often leads to the development of osteoporosis, a degenerative bone disorder. Both type 1 diabetes mellitus (T1DM) and type 2 diabetes mellitus (T2DM) can affect bone mineral density (BMD) and the risk of bone fractures (1). GLP-1 receptor agonists (GLP-1RAs) are a novel class of drugs for T2DM (2); they stimulate insulin secretion, increase $\beta$ cell mass, and suppress glucagon secretion (3-5). Currently, four such drugs available in the United States: exendin-4 or its synthetic version exenatide, liraglutide, albiglutide, and dulaglutide. Various products are in different stages of research and development $(2,6-8)$. The effectiveness of these drugs has led to increasing interest in the mechanisms underlying their effects on bone metabolism. It has been reported that glucagon-like peptide-1 (GLP-1) can enhance BMD and improve bone quality, and the relationship between GLP-1 and bone fractures is still under investigation. GLP-1 can promote bone formation and inhibit bone resorption, but the specific process and related molecular pathways are still not completely understood (9-11). This review summarizes the current state of research into the impact of GLP-1 on bone metabolism and its possible mechanisms.

\section{THE IMPACT OF GLP-1 ON BONE METABOLISM}

\section{The Impact of GLP-1 on BMD}

Glucagon-like peptide- 1 may enhance BMD. In an animal experiment, GLP- 1 and exendin- 4 (a GLP-1 mimetic) reversed the decrease in bone mass of femurs and vertebrae in hyperlipidic and 
hypercaloric Wistar rats (9). In a clinical trial, 61 T2DM patients were divided into three groups randomly: liraglutide $1.8 \mathrm{mg} /$ day or liraglutide $1.2 \mathrm{mg} /$ day or glimepiride $8 \mathrm{mg} /$ day. This research showed no significant differences in BMD among groups in drug use at 52 or 104 weeks (12). The 24 -week use of exenatide in newly diagnosed and treatment-naive patients with T2DM presented no influence on BMD (13). However, 69 T2DM patients receiving metformin were also given either exenatide $(n=36)$ or insulin glargine $(n=33)$. Only patients in the former group experienced significant lowering of body weight and had maintained BMD levels, after 44 weeks of treatment (14). As weight loss results in bone loss (15), and insulin administration may contribute to reduction in bone resorption (16). This result implied that exenatide, in comparison with insulin, may promote BMD while facilitating weight reduction.

\section{The Impact of GLP-1 on Bone Quality}

Glucagon-like peptide-1 may improve bone quality. In ovariectomy (OVX)-induced osteoporosis in aged rats, exendin-4 enhanced bone strength and prevented exacerbation in trabecular microarchitecture (10). In another study, the percent bone volume (BV/TV) and trabecular number (Tb.N) were lowered in diabetic and insulin-resistant (IR) rats, while their trabecular separation (Tb.Sp), trabecular bone pattern factor (Tb.Pf), and structure model index increased, indicating an elevated level of anisotropy in trabecular bone and destruction of the normal bone structure. It was found that GLP-1 could reduce these trends and restore normal bone structure (17). In streptozotocin-induced T1DM Swiss TO mice, liraglutide improved mechanical properties in bone tissue, but failed to reverse cortical microstructure degradation or improve whole bone mechanical properties (18). Furthermore, GLP-1 and glucose-dependent insulinotropic polypeptide double incretin receptor knockout (DIRKO) mice had increased trabecular bone mass and a higher trabecular number compared to wild-type mice, with reduced bone outer diameter, cortical thickness, and cortical area. Mechanical properties of bone matrix were also affected in these mice as evidenced by decreases in yield stress, ultimate stress, and post-yield work-tofracture in DIRKO mice at the level of whole bone. At the tissue level, the maturity level of collagen was $9 \%$ lower in DIRKO mice, which contributed to the lowering of maximum load, hardness, and dissipated energy (19).

\section{The Impact of GLP-1 on Bone Fractures}

The relationship between GLP-1 and the risk of bone fractures has not been fully elucidated. A population-based cohort study using data from the Clinical Practice Research Datalink database (2007-2012) concluded that GLP-1RAs were not related to a decreased risk of bone fractures, independent of dose accumulation and the type of GLP-1 drug (exenatide or liraglutide) used (20). And a case-control study also presented a same conclusion (21). Similarly, a meta-analysis has studied randomized clinical trials (RCTs) comparing GLP-1RAs and other antidiabetic drugs versus a placebo in T2DM patients ( $>24$ weeks). It revealed that GLP-1RAs failed to reduce the risk of bone fractures compared to other antidiabetic agents $[\mathrm{OR}=0.75,95 \%$ confidence interval (CI) $0.28-2.02, P=0.569]$. However, with the lack of data on bone condition, including $\mathrm{BMD}$, microarchitecture, bone quality, calcium, and phosphorus levels at baseline in this study, the results should not be taken as definitive. Furthermore, GLP-1RA is related to decreased body weight, which is unfavorable for bone fractures as weight loss induces mechanical loading and bone mass decrease. These disadvantages can obscure the potential protective effects of GLP-1RA. Additionally, GLP-1RA is associated with gastrointestinal adverse events, which may cause absorption of minerals and nutrients and thereby interfere with the beneficial function of GLP-1RA on bone physiology (22).

It is possible that different GLP-1 agents have divergent effects on bone fractures, as shown in another meta-analysis of RCTs that ended in December 2013. It indicated that liraglutide significantly reduced the risk of bone fractures $(\mathrm{OR}=0.38,95 \% \mathrm{CI}$ $0.17-0.87)$, whereas exenatide increased the risk of bone fractures $(\mathrm{OR}=2.09,95 \%$ CI 1.03-4.21), compared to placebo or other antidiabetic drugs. Clues exist that may help explain the distinct results of liraglutide and exenatide. First, differences in molecular structure result in dissimilar pharmacokinetic profiles. Because liraglutide shares 97\% homology with GLP-1 while exenatide only shares $50 \%$ of GLP-1, it is inferred that liraglutide is more likely to mimic the function of endogenous GLP-1. Second, exenatide tends to cause more weight loss and lower glucose control than liraglutide, which may result in a higher risk of bone fractures (11). In summary, current research is inadequate to explain the effects of GLP-1 and related drugs on bone fracture risk. Furthermore, the incidence of bone fracture is only recorded as adverse reactions instead of being part of routine data collection, which may result in less than complete information. The published animal and human studies on the impact of GLP-1 on bone metabolism are described in Table 1.

\section{THE POTENTIAL MECHANISMS OF THE GLP-1 EFFECTS ON BONE METABOLISM}

The continuous cycle of bone formation and bone resorption in osseous tissue maintains normal bone quality and bone mass. GLP-1 affects both parts of this cycle. Potential mechanisms of GLP-1 are described below and in Figure 1.

\section{Promotion of Bone Formation and Possible Mechanisms GLP-1 Promotes Bone Formation}

Glucagon-like peptide-1 increases the number of osteoblasts. Osteoblast number on the surface of trabecular bone was observed by a histological analysis that demonstrated a significant increase after 16 weeks of exendin- 4 use in OVX rats (10). This result was also confirmed in another study (32).

Glucagon-like peptide-1 promotes the expression of genes related to bone formation. Runx2 encodes osteoblast-specific transcription factor 2 , which is a transcriptional activator of osteoblast differentiation (33). Furthermore, alkaline phosphatase (ALP), collagen type 1 ( $\mathrm{Col} 1)$, and osteocalcin (OC) are common bone formation markers (34); all are upregulated. In old rats with OVX-induced osteoporosis, 16 weeks of exendin-4 administration led to a rise in Runx2, ALP, Col 1, and OC mRNA levels 
TABLE 1 | Published animal and human researches on the impact of GLP-1 on bone metabolism.

\begin{tabular}{|c|c|c|}
\hline Reference & Subjects and design & Main results (BMD, bone quality, and fracture risk) \\
\hline \multicolumn{3}{|l|}{ Animals } \\
\hline \multirow[t]{2}{*}{ Yamada et al. (23) } & GLP-1r knockout mice vs. WT mice & BMD: GLP-1r-1- mice presented lowered cortical BMD \\
\hline & & Bone quality: GLP-1r-/- mice presented diminished bone flexural rigidity \\
\hline \multirow[t]{2}{*}{$\begin{array}{l}\text { Nuche-Berenguer } \\
\text { et al. (17) }\end{array}$} & $\mathrm{T} 2 \mathrm{D}$ rats, $\mathrm{IR}$ rats, and normal rats & $\begin{array}{l}\text { BMD: GLP-1 had a tendency for increasing BMD in T2D and IR rats though the } \\
\text { differences did not reach statistical significance }\end{array}$ \\
\hline & GLP-1 vs. saline (3 days by osmotic pump) & $\begin{array}{l}\text { Bone quality: GLP-1 alleviated enhanced anisotropy and normalized damaged trabecular } \\
\text { bone structure in T2D and IR rats (resulted in a reduction in Tb.Sp, Tb.Pf, and SMI) }\end{array}$ \\
\hline \multirow[t]{2}{*}{$\begin{array}{l}\text { Nuche-Berenguer } \\
\text { et al. (24) }\end{array}$} & $\mathrm{T} 2 \mathrm{D}$ rats, $\mathrm{IR}$ rats, and normal rats & $\begin{array}{l}\text { BMD: exendin- } 4 \text { had a tendency for increasing BMD in T2D and IR rats though the } \\
\text { differences did not reach statistical significance }\end{array}$ \\
\hline & $\begin{array}{l}\text { Saline vs. exendin-4 }(0.1 \mathrm{nmol} / \mathrm{kg} / \mathrm{h} \text { through osmotic } \\
\text { pump for } 3 \text { days) }\end{array}$ & $\begin{array}{l}\text { Bone quality: exendin- } 4 \text { might normalize the damaged trabecular structure in IR and T2D } \\
\text { rats (resulted in a reduction in Tb.Sp, Tb.Pf, and SMI) }\end{array}$ \\
\hline $\begin{array}{l}\text { Nuche-Berenguer } \\
\text { et al. (9) }\end{array}$ & $\begin{array}{l}\text { Wistar HL rats with GLP-1 vs. with exendin- } 4 \text { vs. with } \\
\text { saline vs. normal rats }\end{array}$ & $\begin{array}{l}\text { BMD: GLP-1 and exendin- } 4 \text { improved lowered BMC and BMD of the femur and lumbar } \\
\text { spine of } \mathrm{HL} \text { rats }\end{array}$ \\
\hline Kim et al. (25) & $\begin{array}{l}\text { 4-week-old male T2D OLETF rats with saline vs. } \\
\text { OLETF rats with exendin-4 ( } 5 \mathrm{nmol} / \mathrm{kg} \text { twice a day for } \\
3 \text { weeks) vs. LETO control rats with saline }\end{array}$ & $\begin{array}{l}\text { BMD: exendin- } 4 \text { increased BMD of the femurs in OLETF rats compared to the other two } \\
\text { groups }\end{array}$ \\
\hline
\end{tabular}

Ma et al. (10) 12-month-old female Sprague-Dawley rats

BMD: exendin-4 increased BMC (10 $\mu \mathrm{g} / \mathrm{kg} /$ day) and even increased BMD dose dependently of the femur and lumbar spine

Sham-operated group vs. OVX with vehicle vs.

Bone quality: exendin-4 ( $3 \mu \mathrm{g} / \mathrm{kg} /$ day) improved bone trabecular microarchitecture OVX with $17 \beta$-estradiol $(25 \mu \mathrm{g} / \mathrm{kg} /$ day $)$ vs. OVX with exendin-4 (1, 3, or $10 \mu \mathrm{g} / \mathrm{kg} /$ day)

Mabilleau et al. (26) Male GLP-1r knockout mice vs. control wild-type mice

Sun et al. (27) 2-week-old male diabetic GK rats and age-matched male Wistar rats

GK rats with daily subcutaneous liraglutide injection $(0.4 \mathrm{mg} / \mathrm{kg} /$ day) vs. GK rats with saline vs. Wistar control rats

Mansur et al. (18) STZ-induced diabetic male Swiss TO mice GIP $(25 \mathrm{nmol} / \mathrm{kg})$ vs. liraglutide $(25 \mathrm{nmol} / \mathrm{kg})$ vs. saline

Sun et al. (28) 5-month-old female non-diabetic and OVX Wistar rats similarly, as compared to estradiol. It also improved bone strength of OVX rats

Bone quality: GLP-1r knockout mice presented damaged bone strength and quality

BMD: liraglutide reversed the lowered cortical and trabecular BMD in GK rats

Bone quality: liraglutide ameliorated abnormal cortical and trabecular bone microarchitecture in GK rats

Bone quality: liraglutide improved mechanical properties in bone tissue, but there were no significant results in reversing cortical microstructure degradation or improving whole bone mechanical properties

\section{BMD: exendin-4 increased BMD}

Bone quality: exendin-4 improved trabecular structure and reduced trabecular spacing both in the femur and lumbar vertebrae

Sham + vehicle vs. OVX + vehicle vs.

Fracture risk: exendin-4 might have little influence on the mechanical resistance to fracture in the femur

OVX + exendin-4 (20 $\mu \mathrm{g} / \mathrm{kg} /$ day $)$

Lu et al. (29) 5-month-old female Wistar rats

BMD: liraglutide increased BMD both in the femur and lumbar vertebrae

Sham + saline vs. OVX + saline vs. OVX + liraglutide (0.6 mg/day)

Bone quality: liraglutide improved trabecular structure and reduced trabecular spacing both in the femurs and lumbar vertebrae

Pereira et al. (30) 12-week-old ovariectomized female C57BL/6NCrl mice

BMD: both drugs improved trabecular bone mass

Liraglutide vs. exenatide vs. saline for 4 weeks

Bone quality: both drugs improved bone structure and connectivity, but had no effect on cortical architecture. Both increased osteoclast surfaces but only exenatide enhanced osteoclast number in vivo

Mieczkowska 26-week-old DIRKO mice and wild-type control mice et al. (19)

BMD: DIRKO mice showed higher trabecular bone mass and lower cortical bone mass Bone quality: DIRKO mice presented increased trabecular number but reduced cortical strength. They also showed decreased collagen maturity at the tissue level and resulted in exacerbation in bone mechanical response

\section{Human}

Bunck et al. (14) 69 metformin-treated T2DM patients Exenatide vs. titrated insulin glargine for 44 weeks

BMD: exenatide was not related to significant changes of total BMD and serum markers of bone metabolism, despite a significant body weight decrease. And there was no difference between two groups in the endpoint BMD

Mabilleau et al. (22) A meta-analysis, 28 RCTs were identified Fracture risk: the administration of GLP-1RA was not associated with reduced fracture Either a GLP-1RA use vs. another antidiabetic drug use in T2DM patients for at least 24 weeks 
TABLE 1 | Continued

\begin{tabular}{|c|c|c|}
\hline Reference & Subjects and design & Main results (BMD, bone quality, and fracture risk) \\
\hline Su et al. (11) & $\begin{array}{l}\text { A meta-analysis, } 16 \text { RCTs were identified } \\
\text { Liraglutide or exenatide use vs. placebo or other } \\
\text { diabetic drugs }\end{array}$ & $\begin{array}{l}\text { Fracture risk: liraglutide might reduce the risk of bone fractures while exenatide might } \\
\text { increase the risk of bone fractures }\end{array}$ \\
\hline Driessen et al. (20) & $\begin{array}{l}\text { A population-based cohort, T2DM patients with at } \\
\text { least on prescription for NIAD } \\
\text { GLP-1RA users vs. never GLP-1RA users }\end{array}$ & $\begin{array}{l}\text { Fracture risk: GLP-1 RA administration was not related to decreased risk of fractures } \\
\text { compared to other antidiabetic drugs users }\end{array}$ \\
\hline lepsen et al. (31) & $\begin{array}{l}\text { RCT, } 37 \text { healthy obese women aged } 46 \pm 2 \text { years } \\
\text { With or without liraglutide ( } 1.2 \mathrm{mg} / \text { day) for } 52 \text { weeks } \\
\text { (after a low-calorie-diet-induced } 12 \% \text { weight loss) }\end{array}$ & $\begin{array}{l}\text { BMD: the use of liraglutide reduced the loss of total and arm-leg BMC compared to } \\
\text { control group }\end{array}$ \\
\hline Driessen et al. (21) & $\begin{array}{l}\text { A case-control study } \\
\text { NIAD users vs. GLP-1 RA users }\end{array}$ & $\begin{array}{l}\text { Fracture risk: GLP-1 RA use (current, recent, or past) was not related to reduced fracture } \\
\text { risk as compared to NIAD users }\end{array}$ \\
\hline Gilbert et al. (12) & $\begin{array}{l}\text { 61 T2DM patients aged } 19-79 \text { years } \\
\text { 24-week use of exenatide vs. insulin vs. pioglitazone }\end{array}$ & BMD: there were no apparent differences between groups in mean total BMD \\
\hline Li et al. (13) & $\begin{array}{l}62 \text { newly diagnosed and treatment-naive patients with } \\
\text { T2DM } \\
\text { 24-week use of exenatide vs. insulin vs. pioglitazone }\end{array}$ & BMD: exenatide had no influence on BMD \\
\hline
\end{tabular}

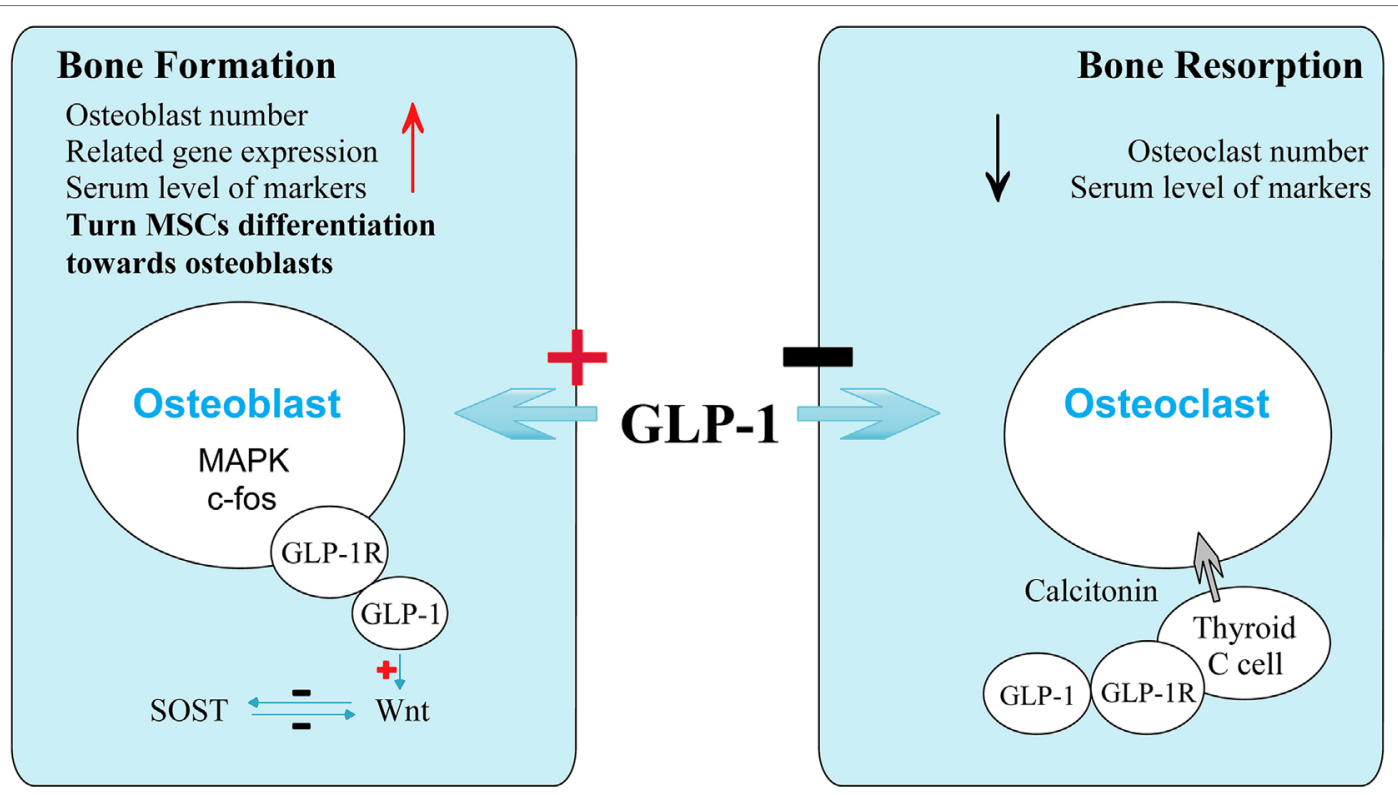

\section{BALANCE}
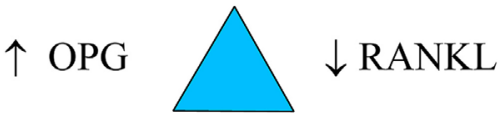

FIGURE 1 | Potential mechanism of glucagon-like peptide-1 (GLP-1) on bone metabolism. GLP-1 promotes bone formation and inhibits bone resorption. For bone formation, GLP-1 results in increasing osteoblast number, gene expression related to bone formation and serum level of bone formation markers. GLP-1 might bind to its receptor on osteoblast and its function is possibly mediated by mitogen-activated protein kinase (MAPK) pathways, Wnt pathways, or c-fos transcription promotion. GLP-1 also turns mesenchymal stem cell (MSC) differentiation from adipocytes toward osteoblasts. For bone resorption, GLP-1 also results in decreasing osteoclast number and serum level of bone resorption markers. But GLP-1 might act through a calcitonin-dependent way in thyroid C cells. Furthermore, GLP-1 increases OPG expression while decreases receptor activator for nuclear factor-kB ligand (RANKL) expression. GLP-1 helps to maintain the balance between bone formation and bone resorption. 
(10). In another report, the use of GLP-1 significantly increased the mRNA level of OC in normal, T2DM, or IR rats (17). The same result was shown in the femurs of Goto-Kakizaki rats in liraglutide use (27). GLP-1 also exerted a similar effect on osteoblastic MC3T3-E1 cells (35). These data further demonstrate, at the gene expression level, that GLP-1 promotes bone formation in various ways.

Glucagon-like peptide-1 is associated with increased serum levels of bone formation markers. The use of exendin- 4 in old OVX rats increased the serum levels of several bone formation markers, including ALP, OC, and N-terminal propeptide of type I procollagen (P1NP) (10). After 52 weeks of treatment with liraglutide, healthy obese women experienced serum P1NP level increases of $16 \%$ on average (31).

\section{GLP-1 Promotes Bone Formation by Lowering Glucose Level}

It was indicated that hyperglycemia was negatively associated with lumbar BMD (36). It has been demonstrated that endogenous GLP-1 could help maintain a normal glycemic level acting through GLP-1 receptors (37). GLP-1 controls the glucose level by stimulating insulin secretion, inhibiting glucagon secretion, and modulating gastric emptying, thus contributing to an enhancement of bone formation (3-5).

\section{The Expression of GLP-1 Receptor on the Osteoblast Function}

It has been established that GLP-1 is involved in important physiological processes through binding to the GLP-1 receptor, which is a cAMP-linked G protein-coupled receptor found in the pancreas and many extra pancreatic tissues. In a study focused on the widely studied mouse osteoblastic MC3T3-E1 cell, the expression of GLP-1 receptor was discovered to be regulated in accordance with glycemic level (38). In another study, it was established that GLP-1 receptors varied in their expression in different stages of osteoblastic cell lines. It can be deduced that the expression level of GLP-1 receptor on osteoblasts decreases with the process of osteoblast maturation (39). Furthermore, an enhanced expression of the GLP-1 receptor gene was observed during the osteogenic differentiation process of adipose-derived stem cells, which have the potential for multiple types of differentiation, including osteogenic differentiation. This result demonstrates that GLP-1 may play a role in the osteogenic differentiation of bone tissue (40).

It is notable that in a study performed by Bernardo, some human GLP-1 could bind to a functional receptor in rat MC3T3-E1 cells with a dependence on time and temperature, but independent of the type of cAMP-linked G protein receptor. To be more specific, the GLP-1 receptor with an attached GLP-1 molecule had the function of instantly hydrolyzing glycosylphosphatidylinositols (GPIs), which generated short-lived inositolphosphoglycans (IPGs), and promoted phosphatidylinositol-3 kinase (PI3K) and mitogen-activated protein kinase (MAPK) activities (35). Another study also demonstrated that GLP-1 participated in the same process in liver and muscle (41). Exendin-4 could also induce the hydrolysis of GPIs but was delayed compared to the natural human GLP-1 amide (35). These results show that GLP-1 might act directly through the GPI/IPG-coupled receptor on osteoblastic MC3T3-E1 cells.

\section{The Pathways of GLP-1 in Promoting Bone Formation}

Wnt pathways may play a significant role in how GLP-1 promotes bone formation. It has been reported that the Wnt pathway was impaired in diabetic rats and that exendin- 4 treatment enhanced bone formation (24). The canonical Wnt pathway, which includes low density lipoprotein receptor-related protein $5 / 6, \beta$-catenin, GSK-3 $\beta$, and $\mathrm{T}$ cell factor (42), promotes osteoblast differentiation and maturation (43); GLP-1 is a direct activator of this pathway (44). Sclerostin, encoded by the SOST gene, is secreted by osteocytes and suppresses bone formation. It binds to bone morphogenetic proteins and negatively affects bone formation by inhibiting ALP activity, type I collagen synthesis, and mineralization (45). Sclerostin also inhibits the Wnt/ $\beta$-catenin signaling pathway (46). Furthermore, it has been observed that exendin- 4 reduced the mRNA and protein levels of SOST/sclerostin in osteocyte-like MLO-Y4 cells and also decreased the serum sclerostin level in T2DM Otsuka Long-Evans Tokushima Fatty rats. The study further proposed that exendin- 4 might bind to GLP-1 receptor, mediated by protein kinase A (PKA), and act on the $\mathrm{Wnt} / \beta$-catenin pathway in osteocytes in order to reduce sclerostin expression and promote bone formation (25).

There are other possible pathways by which GLP-1 could affect bone formation. It has been proposed that GLP-1 could promote c-Fos transcription in osteoblasts in combination with ATP, facilitating the participation of GLP-1 in bone turnover (47). It has been shown that exendin- 4 enhanced the proliferation and differentiation of osteoblasts partly mediated by MAPK pathways, including ERK1/2, p38, and JNK pathways (48). It was also proposed that liraglutide regulated MC3T3-E1 cells differentiation mediated by adenosine monophosphate-activated protein kinase/mammalian target of rapamycin signaling (49).

\section{Suppression of Bone Resorption and Possible Mechanisms GLP-1 Inhibits Bone Resorption}

Glucagon-like peptide-1 has an impact on the number and functioning of osteoclasts. Osteoclast number on the surface of trabecular bone was observed by histological analysis, which demonstrated a significant decrease after 16 weeks of exendin-4 use in OVX rats (10). When ovariectomized mice were treated with liraglutide, exendin-4, or saline, it was observed that the osteoclast number was increased only in the mice that received exendin-4 and a high dose of liraglutide. Although the result was contrary to a previous study, which might partly result from different animal species, assessment method for osteoclast number and drug dose, the bone resorption efficiency of osteoclasts declined in this experiment, leading to decreased bone resorption overall (30).

Glucagon-like peptide-1 administration is associated with reduced serum levels of bone resorption markers. In old rats with OVX-induced osteoporosis, exendin-4 decreased the concentration of C-terminal cross-linked telopeptides of type 
I collagen (CTX-1) and the urinary deoxypyridinoline (DPD)/ creatinine ratio (10). However, 52 weeks of treatment of healthy obese women with liraglutide did not significantly affect serum CTX-1 levels (31). Speculation continues on the inhibitory effect of GLP-1 on bone resorption.

\section{GLP-1 Decreases Bone Resorption through a Calcitonin-Dependent Pathway}

Glucagon-like peptide-1 receptor is expressed in thyroid C cells and can promote the secretion of calcitonin through a cAMPmediated pathway in these cells $(50,51)$. Exendin- 4 treatment caused a higher mRNA level of thyroid calcitonin in wide-type mice, whereas GLP-1 $\mathrm{r}^{-/-}$mice had decreased mRNA levels of calcitonin. Furthermore, GLP-1 $1 \mathrm{r}^{-/}$mice had an enhanced level of urinary DPD, which indicated increased bone resorption. When these GLP-1 $\mathrm{r}^{-/-}$mice were treated with calcitonin, the increase in urinary DPD concentration was alleviated. Therefore, it can be concluded that GLP-1 inhibits bone resorption in a calcitonindependent way (23).

However, the results from preclinical studies have not necessarily extended to success in clinical studies. In rodents, the GLP-1 receptor expression level on thyroid $\mathrm{C}$ cells is high, whereas in humans, the expression of the receptor is lower. The sensitivity of the response of human TT thyroid C cells to GLP-1 that resulted in producing cAMP and releasing calcitonin was different from the rat C cell lines MTC 6-23 and CA-77. Human TT thyroid $\mathrm{C}$ cells were unexpectedly less responsive to GLP-1 (52). In general, GLP-1 may inhibit bone resorption via a calcitonin-dependent pathway, but this hypothesis still needs to be explored further.

\section{The Impact of GLP-1 on the Balance between Bone Formation and Bone Resorption}

Normal bone metabolism in humans involves both bone formation and bone resorption in a balanced state of equilibrium. These dynamic processes involve the bone multicellular unit composed of osteoblasts, osteoclasts, and osteocytes within bone matrix (53). Osteoblasts and adipocytes are derived from mesenchymal stem cells (MSCs) (54). Liraglutide has been found to influence MSC differentiation toward osteoblasts rather than adipocytes (29). In a further exploration of the molecular mechanisms of this effect, it was revealed that GLP-1 increased hMSC proliferation, inhibited the process of their early adipogenesis, and reduced cell death in them. In this study, it was also pointed out that two potential signaling pathways involved in hMSC differentiation into adipocytes might be the targets for GLP-1: MAPK and PKC pathways (55). It has also been speculated that GLP-1 directed the differentiation tendency via MAPK and Wnt signaling pathways to promote Runx2 activity (28). In another research, it was demonstrated that GLP-1 promoted MSC differentiation direction into osteoblasts though acting on PKA/ $\beta$-catenin and PKA/PI3K/AKT/GSK3 $\beta$ pathways (32). It was also proposed that the target might be extracellular signal-regulated kinase signaling pathway (56). Furthermore, two studies revealed new molecular mechanisms for exendin- 4 to affect MSC activities in myocardial infarction, which might present a hint for the same process in bone metabolism. First, exendin- 4 activated GLP-1R/cAMP/PKA pathway and attenuated endoplasmic reticulum stress in order to inhibit bone marrow-derived MSC apoptosis mediated by oxygen, glucose, and serum deprivation (57). Second, exendin-4 might regulate MSC growth, mobilization, and survival partly through PI3K/ Akt pathway (58). However, further results are needed in order to make an explicit explanation for this issue. Osteoclasts are derived from mature monocytes and macrophages (59); their maturation is regulated by osteoblast-derived cytokines. Among these, osteoprotegerin (OPG), receptor activator for nuclear factor- $\mathrm{KB}$ ligand (RANKL), and receptor activator for nuclear factor- $\mathrm{KB}$ form a triangular relationship that regulates osteoclast differentiation, activation, and apoptosis. Most of the factors that promote osteoclastogenesis function in osteoclasts perform through enhancing RANKL expression on osteoblasts. Twelvemonth-old female Sprague-Dawley aged OVX rats have been observed to increase the mRNA level of OPG while decreasing RANKL mRNA after 16 weeks of exendin-4 use (10). It was also revealed in another study that GLP-1 had more effect on OPG than RANKL in mRNA and protein level of the isolated Wistar rat tibiae (9). Therefore, GLP-1 not only promotes bone formation but also inhibits bone resorption. And to further prove this point, the research by Ma mentioned before focused on aged ovariectomized rats, since aged osteopenia tends to more reduction in bone formation while postmenopausal osteopenia tends to more increase in bone resorption. This study revealed that GLP-1 might have dual anti-osteporosis function on bone tissue (10).

\section{CONCLUSION AND EXPECTATIONS}

Many scientific investigations have focused on the impact and mechanisms of therapies based on insulin-stimulating hormones, such as GLP-1. The evidence indicates that such therapies may enhance BMD and improve bone quality, but the relationship between GLP-1 and bone fractures is still controversial. Further investigations of the relevant mechanisms have indicated that GLP-1 acts on bone tissue by promoting bone formation and inhibiting bone resorption. Furthermore, the homeostasis of bone formation and resorption is essential to bone health and might be maintained by GLP-1 in normal bones and restored by GLP-1 in unhealthy bones. However, the specific molecular mechanisms responsible for the effects of GLP-1 have still not been fully elucidated. Therefore, although several studies have been conducted, additional multiple-centered RCTs are needed to analyze different parts of bone tissue in patients with different metabolic statuses, being treated with different versions of GLP-1RAs. Elucidating the specific processes and associated molecular pathways will aid in clarifying the impact of GLP-1 on bone metabolism and the mechanisms involved.

\section{AUTHOR CONTRIBUTIONS}

All the authors contributed equally to the writing, revision, and editing of this manuscript. 


\section{FUNDING}

This work was supported by the National Natural Science Foundation for Youths (Grant Nos. 81401852), the Natural

\section{REFERENCES}

1. Vestergaard P. Discrepancies in bone mineral density and fracture risk in patients with type 1 and type 2 diabetes - a meta-analysis. Osteoporos Int (2007) 18(4):427-44. doi:10.1007/s00198-006-0253-4

2. Seino Y, Kaneko S, Fukuda S, Osonoi T, Shiraiwa T, Nishijima K, et al. Combination therapy with liraglutide and insulin in Japanese patients with type 2 diabetes: a 36-week, randomized, double-blind, parallel-group trial. J Diabetes Investig (2016) 7(4):565-73. doi:10.1111/jdi.12457

3. Mojsov S, Weir GC, Habener JF. Insulinotropin: glucagon-like peptide I (7-37) co-encoded in the glucagon gene is a potent stimulator of insulin release in the perfused rat pancreas. J Clin Invest (1987) 79(2):616-9. doi:10.1172/ JCI112855

4. Sasaki S, Miyatsuka T, Matsuoka TA, Takahara M, Yamamoto Y, Yasuda T, et al. Activation of GLP-1 and gastrin signalling induces in vivo reprogramming of pancreatic exocrine cells into beta cells in mice. Diabetologia (2015) 58(11):2582-91. doi:10.1007/s00125-015-3728-z

5. Hare KJ, Knop FK, Asmar M, Madsbad S, Deacon CF, Holst JJ, et al. Preserved inhibitory potency of GLP-1 on glucagon secretion in type 2 diabetes mellitus. J Clin Endocrinol Metab (2009) 94(12):4679-87. doi:10.1210/jc.2009-0921

6. Sheu WH, Brunell SC, Blase E. Efficacy and tolerability of exenatide twice daily and exenatide once weekly in Asian versus White patients with type 2 diabetes mellitus: a pooled analysis. Diabetes Res Clin Pract (2016) 114:160-72. doi:10.1016/j.diabres.2015.12.004

7. Nauck MA, Stewart MW, Perkins C, Jones-Leone A, Yang F, Perry C, et al. Efficacy and safety of once-weekly GLP-1 receptor agonist albiglutide (HARMONY 2): 52 week primary endpoint results from a randomised, placebo-controlled trial in patients with type 2 diabetes mellitus inadequately controlled with diet and exercise. Diabetologia (2016) 59(2):266-74. doi:10.1007/ s00125-015-3795-1

8. Odawara M, Miyagawa J, Iwamoto N, Takita Y, Imaoka T, Takamura T. Onceweekly glucagon-like peptide-1 receptor agonist dulaglutide significantly decreases glycated haemoglobin compared with once-daily liraglutide in Japanese patients with type 2 diabetes: 52 weeks of treatment in a randomized phase III study. Diabetes Obes Metab (2016) 18(3):249-57. doi:10.1111/ dom. 12602

9. Nuche-Berenguer B, Lozano D, Gutierrez-Rojas I, Moreno P, Marinoso ML, Esbrit P, et al. GLP-1 and exendin-4 can reverse hyperlipidic-related osteopenia. J Endocrinol (2011) 209(2):203-10. doi:10.1530/JOE-11-0015

10. Ma X, Meng J, Jia M, Bi L, Zhou Y, Wang Y, et al. Exendin-4, a glucagon-like peptide-1 receptor agonist, prevents osteopenia by promoting bone formation and suppressing bone resorption in aged ovariectomized rats. J Bone Miner Res (2013) 28(7):1641-52. doi:10.1002/jbmr.1898

11. Su B, Sheng H, Zhang M, Bu L, Yang P, Li L, et al. Risk of bone fractures associated with glucagon-like peptide-1 receptor agonists' treatment: a meta-analysis of randomized controlled trials. Endocrine (2015) 48(1):107-15. doi:10.1007/ s12020-014-0361-4

12. Gilbert MP, Marre M, Holst JJ, Garber A, Baeres FM, Thomsen H, et al. Comparison of the long-term effects of liraglutide and glimepiride monotherapy on bone mineral density in patients with type 2 diabetes. Endocr Pract (2016) 22(4):406-11. doi:10.4158/EP15758.OR

13. Li R, Xu W, Luo S, Xu H, Tong G, Zeng L, et al. Effect of exenatide, insulin and pioglitazone on bone metabolism in patients with newly diagnosed type 2 diabetes. Acta Diabetol (2015) 52(6):1083-91. doi:10.1007/s00592-015-0792-2

14. Bunck MC, Eliasson B, Corner A, Heine RJ, Shaginian RM, Taskinen MR, et al. Exenatide treatment did not affect bone mineral density despite body weight reduction in patients with type 2 diabetes. Diabetes Obes Metab (2011) 13(4):374-7. doi:10.1111/j.1463-1326.2010.01355.x

15. Jensen LB, Kollerup G, Quaade F, Sorensen OH. Bone minerals changes in obese women during a moderate weight loss with and without calcium supplementation. J Bone Miner Res (2001) 16(1):141-7. doi:10.1359/jbmr. 2001.16.1.141
Science Foundation of Shanghai (No. 14ZR1424000), and "Chen Guang" Project of the Shanghai Municipal Education Commission and the Shanghai Education Development Foundation (No. 14CG14).

16. Bjarnason NH, Henriksen EE, Alexandersen P, Christgau S, Henriksen DB, Christiansen C. Mechanism of circadian variation in bone resorption. Bone (2002) 30(1):307-13. doi:10.1016/S8756-3282(01)00662-7

17. Nuche-Berenguer B, Moreno P, Esbrit P, Dapia S, Caeiro JR, Cancelas J, et al. Effect of GLP-1 treatment on bone turnover in normal, type 2 diabetic, and insulin-resistant states. Calcif Tissue Int (2009) 84(6):453-61. doi:10.1007/ s00223-009-9220-3

18. Mansur SA, Mieczkowska A, Bouvard B, Flatt PR, Chappard D, Irwin N, et al. Stable incretin mimetics counter rapid deterioration of bone quality in type 1 diabetes mellitus. J Cell Physiol (2015) 230(12):3009-18. doi:10.1002/ jcp. 25033

19. Mieczkowska A, Mansur S, Bouvard B, Flatt PR, Thorens B, Irwin N, et al. Double incretin receptor knock-out (DIRKO) mice present with alterations of trabecular and cortical micromorphology and bone strength. Osteoporos Int (2015) 26(1):209-18. doi:10.1007/s00198-014-2845-8

20. Driessen JH, Henry RM, van Onzenoort HA, Lalmohamed A, Burden AM, Prieto-Alhambra D, et al. Bone fracture risk is not associated with the use of glucagon-like peptide-1 receptor agonists: a population-based cohort analysis. Calcif Tissue Int (2015) 97(2):104-12. doi:10.1007/s00223-015-9993-5

21. Driessen JH, van Onzenoort HA, Starup-Linde J, Henry R, Burden AM, NeefC, et al. Use of glucagon-like-peptide 1 receptor agonists and risk of fracture as compared to use of other anti-hyperglycemic drugs. Calcif Tissue Int (2015) 97(5):506-15. doi:10.1007/s00223-015-0037-y

22. Mabilleau G, Mieczkowska A, Chappard D. Use of glucagon-like peptide-1 receptor agonists and bone fractures: a meta-analysis of randomized clinical trials. J Diabetes (2014) 6(3):260-6. doi:10.1111/1753-0407.12102

23. Yamada C, Yamada Y, Tsukiyama K, Yamada K, Udagawa N, Takahashi N, et al. The murine glucagon-like peptide-1 receptor is essential for control of bone resorption. Endocrinology (2008) 149(2):574-9. doi:10.1210/en.2007-1292

24. Nuche-Berenguer B, Moreno P, Portal-Nunez S, Dapia S, Esbrit P, VillanuevaPenacarrillo ML. Exendin-4 exerts osteogenic actions in insulin-resistant and type 2 diabetic states. Regul Pept (2010) 159(1-3):61-6. doi:10.1016/j. regpep.2009.06.010

25. Kim JY, Lee SK, Jo KJ, Song DY, Lim DM, Park KY, et al. Exendin-4 increases bone mineral density in type 2 diabetic OLETF rats potentially through the down-regulation of SOST/sclerostin in osteocytes. Life Sci (2013) 92(10):53340. doi:10.1016/j.lfs.2013.01.001

26. Mabilleau G, Mieczkowska A, Irwin N, Flatt PR, Chappard D. Optimal bone mechanical and material properties require a functional glucagon-like peptide-1 receptor. J Endocrinol (2013) 219(1):59-68. doi:10.1530/JOE-13-0146

27. Sun HX, Lu N, Luo X, Zhao L, Liu JM. Liraglutide, the glucagon-like peptide-1 receptor agonist, has anabolic bone effects in diabetic Goto-Kakizaki rats. J Diabetes (2015) 7(4):584-8. doi:10.1111/1753-0407.12282

28. Sun HX, Lu N, Liu DM, Zhao L, Sun LH, Zhao HY, et al. The bone-preserving effects of exendin-4 in ovariectomized rats. Endocrine (2016) 51(2):323-32. doi:10.1007/s12020-015-0667-x

29. Lu N, Sun H, Yu J, Wang X, Liu D, Zhao L, et al. Glucagon-like peptide-1 receptor agonist liraglutide has anabolic bone effects in ovariectomized rats without diabetes. PLoS One (2015) 10(7):e0132744. doi:10.1371/journal.pone. 0132744

30. Pereira M, Jeyabalan J, Jorgensen CS, Hopkinson M, Al-Jazzar A, Roux JP, et al. Chronic administration of glucagon-like peptide- 1 receptor agonists improves trabecular bone mass and architecture in ovariectomised mice. Bone (2015) 81:459-67. doi:10.1016/j.bone.2015.08.006

31. Iepsen EW, Lundgren JR, Hartmann B, Pedersen O, Hansen T, Jorgensen NR, et al. GLP-1 receptor agonist treatment increases bone formation and prevents bone loss in weight-reduced obese women. J Clin Endocrinol Metab (2015) 100(8):2909-17. doi:10.1210/jc.2015-1176

32. Meng J, Ma X, Wang N, Jia M, Bi L, Wang Y, et al. Activation of GLP-1 receptor promotes bone marrow stromal cell osteogenic differentiation through beta-catenin. Stem Cell Reports (2016) 6(4):579-91. doi:10.1016/j. stemcr.2016.02.002 
33. Ducy P, Zhang R, Geoffroy V, Ridall AL, Karsenty G. Osf2/Cbfa1: a transcriptional activator of osteoblast differentiation. Cell (1997) 89(5):747-54. doi:10.1016/S0092-8674(00)80257-3

34. Yoshimura N, Muraki S, Oka H, Kawaguchi H, Nakamura K, Akune T. Biochemical markers of bone turnover as predictors of osteoporosis and osteoporotic fractures in men and women: 10-year follow-up of the Taiji cohort. Mod Rheumatol (2011) 21(6):608-20. doi:10.1007/s10165-011-0455-2

35. Nuche-Berenguer B, Portal-Nunez S, Moreno P, Gonzalez N, Acitores A, Lopez-Herradon A, et al. Presence of a functional receptor for GLP-1 in osteoblastic cells, independent of the cAMP-linked GLP-1 receptor. J Cell Physiol (2010) 225(2):585-92. doi:10.1002/jcp.22243

36. Terzi R, Dindar S, Terzi H, Demirtas O. Relationships among the metabolic syndrome, bone mineral density, bone turnover markers, and hyperglycemia. Metab Syndr Relat Disord (2015) 13(2):78-83. doi:10.1089/met.2014.0074

37. Lamont BJ, Li Y, Kwan E, Brown TJ, Gaisano H, Drucker DJ. Pancreatic GLP-1 receptor activation is sufficient for incretin control of glucose metabolism in mice. J Clin Invest (2012) 122(1):388-402. doi:10.1172/JCI42497

38. Aoyama E, Watari I, Podyma-Inoue KA, Yanagishita M, Ono T. Expression of glucagon-like peptide-1 receptor and glucose-dependent insulinotropic polypeptide receptor is regulated by the glucose concentration in mouse osteoblastic MC3T3-E1 cells. Int J Mol Med (2014) 34(2):475-82. doi:10.3892/ ijmm.2014.1787

39. Pacheco-Pantoja EL, Ranganath LR, Gallagher JA, Wilson PJ, Fraser WD. Receptors and effects of gut hormones in three osteoblastic cell lines. BMC Physiol (2011) 11:12. doi:10.1186/1472-6793-11-12

40. Jeon YK, Bae MJ, Kim JI, Kim JH, Choi SJ, Kwon SK, et al. Expression of glucagon-like peptide 1 receptor during osteogenic differentiation of adipose-derived stem cells. Endocrinol Metab (Seoul) (2014) 29(4):567-73. doi:10.3803/EnM.2014.29.4.567

41. Villanueva-Penacarrillo ML, Delgado E, Trapote MA, Alcantara A, Clemente F, Luque MA, et al. Glucagon-like peptide-1 binding to rat hepatic membranes. J Endocrinol (1995) 146(1):183-9. doi:10.1677/joe.0.1460183

42. Etheridge SL, Spencer GJ, Heath DJ, Genever PG. Expression profiling and functional analysis of wnt signaling mechanisms in mesenchymal stem cells. Stem Cells (2004) 22(5):849-60. doi:10.1634/stemcells.22-5-849

43. Shi YC, Worton L, Esteban L, Baldock P, Fong C, Eisman JA, et al. Effects of continuous activation of vitamin $\mathrm{D}$ and Wnt response pathways on osteoblastic proliferation and differentiation. Bone (2007) 41(1):87-96. doi:10.1016/j. bone.2007.04.174

44. Liu Z, Habener JF. Glucagon-like peptide-1 activation of TCF7L2-dependent Wnt signaling enhances pancreatic beta cell proliferation. J Biol Chem (2008) 283(13):8723-35. doi:10.1074/jbc.M706105200

45. Winkler DG, Sutherland MK, Geoghegan JC, Yu C, Hayes T, Skonier JE, et al. Osteocyte control of bone formation via sclerostin, a novel BMP antagonist. EMBO J (2003) 22(23):6267-76. doi:10.1093/emboj/cdg599

46. Veverka V, Henry AJ, Slocombe PM, Ventom A, Mulloy B, Muskett FW, et al. Characterization of the structural features and interactions of sclerostin: molecular insight into a key regulator of Wnt-mediated bone formation. J Biol Chem (2009) 284(16):10890-900. doi:10.1074/jbc.M807994200

47. Pacheco-Pantoja EL, Dillon JP, Wilson PJ, Fraser WD, Gallagher JA. c-Fos induction by gut hormones and extracellular ATP in osteoblastic-like cell lines. Purinergic Signal (2016) 12(4):647-51. doi:10.1007/s11302-016-9526-3

48. Feng Y, Su L, Zhong X, Guohong W, Xiao H, Li Y, et al. Exendin-4 promotes proliferation and differentiation of MC3T3-E1 osteoblasts by MAPKs activation. J Mol Endocrinol (2016) 56(3):189-99. doi:10.1530/JME-15-0264
49. Hu XK, Yin XH, Zhang HQ, Guo CF, Tang MX. Liraglutide attenuates the osteoblastic differentiation of MC3T3E1 cells by modulating AMPK/ mTOR signaling. Mol Med Rep (2016) 14(4):3662-8. doi:10.3892/mmr. 2016.5729

50. Crespel A, De Boisvilliers F, Gros L, Kervran A. Effects of glucagon and glucagon-like peptide-1-(7-36) amide on C cells from rat thyroid and medullary thyroid carcinoma CA-77 cell line. Endocrinology (1996) 137(9):3674-80. doi:10.1210/endo.137.9.8756532

51. Lamari Y, Boissard C, Moukhtar MS, Jullienne A, Rosselin G, Garel JM. Expression of glucagon-like peptide 1 receptor in a murine $C$ cell line: regulation of calcitonin gene by glucagon-like peptide 1. FEBS Lett (1996) 393(2-3):248-52. doi:10.1016/0014-5793(96)00895-2

52. Bjerre Knudsen L, Madsen LW, Andersen S, Almholt K, de Boer AS, Drucker DJ, et al. Glucagon-like peptide-1 receptor agonists activate rodent thyroid C-cells causing calcitonin release and C-cell proliferation. Endocrinology (2010) 151(4):1473-86. doi:10.1210/en.2009-1272

53. Hauge EM, Qvesel D, Eriksen EF, Mosekilde L, Melsen F. Cancellous bone remodeling occurs in specialized compartments lined by cells expressing osteoblastic markers. J Bone Miner Res (2001) 16(9):1575-82. doi:10.1359/ jbmr.2001.16.9.1575

54. Jiang Y, Jahagirdar BN, Reinhardt RL, Schwartz RE, Keene CD, Ortiz-Gonzalez XR, et al. Pluripotency of mesenchymal stem cells derived from adult marrow. Nature (2002) 418(6893):41-9. doi:10.1038/nature00870

55. Sanz C, Vazquez P, Blazquez C, Barrio PA, Alvarez MM, Blazquez E. Signaling and biological effects of glucagon-like peptide 1 on the differentiation of mesenchymal stem cells from human bone marrow. Am J Physiol Endocrinol Metab (2010) 298(3):E634-43. doi:10.1152/ajpendo.00460.2009

56. Lee HM, Joo BS, Lee CH, Kim HY, Ock JH, Lee YS. Effect of glucagon-like peptide- 1 on the differentiation of adipose-derived stem cells into osteoblasts and adipocytes. J Menopausal Med (2015) 21(2):93-103. doi:10.6118/ jmm.2015.21.2.93

57. He J, Wang C, Sun Y, Lu B, Cui J, Dong N, et al. Exendin-4 protects bone marrow-derived mesenchymal stem cells against oxygen/glucose and serum deprivation-induced apoptosis through the activation of the cAMP/PKA signaling pathway and the attenuation of ER stress. Int J Mol Med (2016) 37(4):889-900. doi:10.3892/ijmm.2016.2509

58. Zhou H, Li D, Shi C, Xin T, Yang J, Zhou Y, et al. Effects of Exendin-4 on bone marrow mesenchymal stem cell proliferation, migration and apoptosis in vitro. Sci Rep (2015) 5:12898. doi:10.1038/srep12898

59. Udagawa N, Takahashi N, Akatsu T, Tanaka H, Sasaki T, Nishihara T, et al. Origin of osteoclasts: mature monocytes and macrophages are capable of differentiating into osteoclasts under a suitable microenvironment prepared by bone marrow-derived stromal cells. Proc Natl Acad Sci U S A (1990) 87(18):7260-4. doi:10.1073/pnas.87.18.7260

Conflict of Interest Statement: The authors declare that the research was conducted in the absence of any commercial or financial relationships that could be construed as a potential conflict of interest.

Copyright (c) 2017 Zhao, Liang, Yang, Yu and Qu. This is an open-access article distributed under the terms of the Creative Commons Attribution License (CC BY). The use, distribution or reproduction in other forums is permitted, provided the original author(s) or licensor are credited and that the original publication in this journal is cited, in accordance with accepted academic practice. No use, distribution or reproduction is permitted which does not comply with these terms. 